\title{
TENDÊNCIA DAS SÉRIES TEMPORAIS DE PRECIPITAÇÃO DA REGIÃO SUL DO BRASIL
}

\author{
ADILSON PINHEIRO ${ }^{1}$, REGINA LUIZA GOUVEAA GRACIANO ${ }^{2}$, DIRCEU LUÍS SEVERO ${ }^{3}$ \\ ${ }^{1}$ Fundação Universidade Regional de Blumenau(FURB), Departamento de Engenharia Civil, Blumenau, SC, Brasil \\ ${ }^{2}$ FURB, Departamento de Engenharia Ambiental, Blumenau, SC, Brasil \\ ${ }^{3}$ FURB, Departamento de Física, Blumenau, SC, Brasil \\ pinheiro@furb.br, regina.graciano@hotmail.com, severo@furb.br \\ Recebido Julho de 2011 - Aceito Fevereiro de 2013
}

\begin{abstract}
RESUMO
O objetivo deste trabalho é avaliar a presença de tendências nas séries temporais de precipitação no Sul do Brasil. Foram analisadas séries temporais diárias, mensais e anuais de 18 estações pluviométricas. As distribuições de probabilidade normal e de extremos tipo I foram empregadas para análise dos dados. Foi, ainda, aplicado o teste de tendência de Mann-Kendall na detecção de tendências ou de variabilidades climáticas. Os resultados mostram uma tendência positiva dos máximos diários anuais ao longo do tempo, assim como significativa elevação dos totais mensais e anuais na maioria das estações. O teste de tendência de Mann-Kendal mostra mudanças estatisticamente significativas, ao nível de $95 \%$, em 16 das 18 estações pluviométricas analisadas.
\end{abstract}

Palavras chaves: Séries temporais de precipitação, Tendências climáticas, teste de Mann-Kendall.

\begin{abstract}
TREND ON PRECIPITATION TIME SERIES IN SOUTHERN BRAZIL
The aim of this study is to evaluate the occurrence of trends in time series of precipitation in southern Brazil. We analyzed daily, monthly and yearly time series from 18 rain gauges station. The normal and type I extreme probability distributions were used for data analysis. The Mann-Kendall test was also to detect trends or climatic variability. The results show a positive trend of daily annual maximum over time, as well as a significant increase of monthly and annual totals for most stations. The Mann-Kendal trend test shows statistically significant changes at a $95 \%$ level on 16 out of the 18 analyzed time series.
\end{abstract}

Keywords: Time series of precipitation, climate trends, Mann-Kendall test

\section{INTRODUÇÃO}

O clima da Terra sempre esteve sujeito a mudanças, moduladas por ciclos longos ou curtos, registrados na história da humanidade. Algumas das grandes ondas de migrações humanas são em parte devidas a fenômenos climáticos, que podem ser explicados por processos naturais, como alterações no eixo de rotação da Terra, explosões solares e dispersão de aerossóis emitidos pelas atividades vulcânicas. Diversos outros eventos, mais localizados, como furacões, enchentes, degelo, ondas de calor, que até o século XX eram considerados fenômenos naturais, recentemente, têm sido atribuídos às mudanças climáticas globais.

O crescente interesse no estudo da variabilidade climática se deve à hipótese de que os efeitos das atividades humanas sobre o clima, sobrepostos ao sinal base dos processos climáticos naturais, acabam mascarando ou intensificando seus impactos (Obregón Párraga, 2003), o que tornaria a situação em curso ainda mais crítica.

Gallant et al. (2007), investigando tendências nas séries de precipitação da Austrália para dois períodos (19102005 e 1950-2005), encontraram tendências lineares para todos os índices de precipitação em cada estação analisada. A avaliação qualitativa das séries temporais mostrou grande redução na precipitação sazonal e anual desde os anos 1950 no litoral leste e na região sudoeste e, desde a década de 1970, para o sudeste do país. Resultados similares foram verificados por Haylock e Nicholls (2000). Roy e Balling (2004), também encontraram tendências de extremos na Índia. Gemmer et al. (2004) encontraram tendências positivas e negativas em várias estações pluviométricas da China no período de 1951 a 2002. 
Na América do Sul, Haylock et al. (2006) investigaram tendências na distribuição de valores extremos nas séries de precipitação no sudeste da América do Sul no período de 1960 a 2000 e encontraram tendências para condições mais úmidas no sul do Brasil, Paraguai, Uruguai e no norte e centro da Argentina. A análise indicou tendências positivas no número anual de dias com precipitação acima de $10 \mathrm{~mm}$ e acima de $20 \mathrm{~mm}$, um indicativo de aumento na intensidade e frequência de dias com chuvas intensas. Resultados semelhantes foram encontrados por Alexander et al. (2006) para a mesma região.

Sant'Anna Neto (1999) analisou séries de totais mensais e anuais de 396 postos pluviométricos da rede básica do estado de São Paulo, pertencentes ao Departamento de Água e Energia Elétrica (DAEE). O autor considerou que houve tendência de incremento das precipitações, uma vez que o total anual de 1892 , ano extremamente chuvoso, foi ultrapassado 20 anos depois pelo evento de 1911 e este, por sua vez, em 1938 e este último pelo total anual de 1983.

Silva et al. (2010) analisando séries temporais de precipitação de todo o Brasil para o período 1961 a 2008, encontraram padrões diferenciados e muito regionalizados nas tendências de aumento e diminuição das precipitações. Em termos anuais, a faixa leste da região Sul do Brasil destaca-se como área com tendências positivas significativas, desde o centro do Rio Grande do Sul até o Paraná. Segundo Minuzzi e Caramori (2011) desde meados do século XX o estado do Paraná vem apresentando uma tendência de aumento no volume pluviométrico, principalmente, nos meses de verão e de primavera. No verão o total de chuva teve um acréscimo de 17 a $37 \mathrm{~mm}$ por década, enquanto na primavera esta tendência foi de 16 a $42 \mathrm{~mm}$ sendo que algumas estações hidrológicas apresentaram esta tendência significativa em ambos os períodos sazonais.

Campos et al. (2006) encontraram forte aumento da temperatura do ar (mais intenso para a temperatura mínima) e um aumento dos totais anuais de precipitação ao longo do período de 1911 a 2006 no estado de Santa Catarina. Para o Rio Grande do Sul, Sansigolo e Kayano (2010) constataram tendências significativas de aumento de $93 \mathrm{~mm}$ em 100 anos, na média sazonal de verão, provavelmente devido a um aumento da cobertura de nuvens que é consistente com a tendência de aumento das temperaturas mínimas.

Dentro deste contexto, o objetivo deste trabalho é verificar a presença de tendências nas séries de precipitação na região Sul do Brasil em diferentes escalas de tempo.

\section{MATERIAL E MÉTODOS}

A área de estudo deste trabalho é a região Sul do Brasil, onde foram selecionadas estações pluviométricas com dados diários cedidos pela Agência Nacional de Águas (ANA).
Para a seleção das estações pluviométricas, o critério estabelecido foi que a série temporal deveria ser contínua, com comprimento superior a 50 anos, conforme recomendam Streck et al. (2009), com período de falhas contínuas inferior a 12 meses e distribuídas nos estados do Paraná, Santa Catarina e Rio Grande do Sul. Com esses critérios foram selecionadas dezoito estações pluviométricas, sendo oito localizadas no estado do Paraná, cinco no estado de Santa Catarina e cinco no estado do Rio Grande do Sul.

As falhas nas séries mensais foram preenchidas pelo método de ponderação regional (Tucci, 2004). Para cada falha detectada em determinada estação pluviométrica, procurou-se no conjunto de estações disponíveis no portal do Sistema de Informações de Recursos Hídricos da ANA (http://portal.snirh. ana.gov.br), três localizadas no entorno, o mais próximo possível daquela a ser preenchida, que possibilitassem a aplicação do método.

Cada série original foi decomposta em séries parciais com comprimento de 30 anos. As séries parciais são sucessivas, de modo que cada série completa, de $m$ anos de dados, permitiu a formação de $n$ séries parciais, onde $n=m-30+1$. A evolução temporal de cada estação foi analisada a partir dos valores característicos (total anual, total mensal, máximo diário com período de retorno estabelecido) obtidos para cada série parcial. O comprimento de 30 anos da série parcial permite considerar que os processos cíclicos de curto prazo estejam incorporados, assim como, a existência de estacionaridade na série. Para a série completa, a hipótese de estacionariedade não pode ser garantida, diante da possibilidade de existência de tendências e ciclos na sua evolução temporal.

As séries de precipitação com excedência de ocorrência, para uma frequência estabelecida, foram obtidas pela aplicação de uma distribuição de probabilidade a cada série parcial. Sendo assim, para as precipitações totais mensais e anuais foi aplicada a distribuição normal e para as séries de máximos valores diários anuais foi aplicada a distribuição de extremos Tipo I, conhecida como distribuição de Gumbel (Naghettini e Pinto, 2007). Para a série de extremos anuais foi adotada a frequência de excedência correspondente ao período de retorno de 100 anos, o qual é o intervalo de tempo, em média, com que um evento é igualado ou superado pelo menos uma vez.

Assim, para cada série parcial foi determinado o valor da precipitação máxima com esta frequência de excedência. A partir dos valores destas precipitações máximas obtidos de cada série parcial verificou-se sua evolução temporal, de modo a demonstrar eventuais mudanças no seu comportamento climatológico.

As precipitações máximas, com período de retorno de 100 anos, obtidas em cada série parcial, foram distribuídas graficamente, sendo ajustada uma curva de tendência. Esta 
tendência foi expressa por um modelo linear do tipo $y=a+$ $b x$, onde $\mathrm{x}$ é a variável tempo, y a precipitação máxima com período de retorno de 100 anos, $a$ o valor da reta ajustada para o tempo $t=0$ e $b$ é o coeficiente angular. Para cada curva de tendência foi realizada a estimativa da significância, ao nível de $5 \%$, dos coeficientes da regressão obtidos, usando-se o software Statistica.

Visando a detecção de tendências e/ou mudanças bruscas na média de longo prazo foi utilizado o teste não paramétrico de Mann-Kendall (Sneyers, 1975). Segundo Obregón Párraga (2003) a vantagem de se utilizar este teste, é que ele usa a magnitude relativa dos valores da série, filtrando valores extremos. Este método também foi empregado por Burn et al. (2010) para detecção de tendências em eventos hidrológicos no Canadá.

Brevemente, pode-se descrever o teste de MannKendall da seguinte forma: considerando uma dada série temporal $Y_{i}$ de $\mathrm{N}$ termos $(i=1, \ldots, N)$, calcula-se a soma dada pela equação: $t_{n}=\sum_{i=1}^{N} m_{i}$, onde $m_{i}$ é o número de termos da série, relativo ao valor $Y_{i}$, cujos termos anteriores são inferiores ao mesmo. Para um valor de $N$ grande, sob a hipótese nula $H_{0}$ de ausência de tendência, $t_{n}$ apresentará uma distribuição normal com média $\mathrm{E}\left(t_{n}\right)$ e variância $\operatorname{Var}\left(t_{n}\right)$, dados pelas seguintes equações:

$$
E\left(t_{n}\right)=\frac{n(n-1)}{4} \quad \text { e } \quad \operatorname{Var}\left(t_{n}\right)=\frac{n(n-1)(2 n+5)}{72}
$$

A hipótese nula pode ser rejeitada testando a significância estatística de $t_{n}$ utilizando um teste bilateral obtido através da seguinte relação:

$$
u\left(t_{n}\right)=\frac{\left(t_{n}-E\left(t_{n}\right)\right)}{\left(\operatorname{Var}\left(t_{n}\right)\right)^{\frac{1}{2}}}
$$

A hipótese nula é aceita sempre que $u\left(t_{n}\right)$ for maior do que $\alpha_{0}$, sendo $\alpha_{0}$ o valor do nível de significância dado pela distribuição normal. A rejeição da hipótese nula implica em aceitar que em algum ponto da série temporal existe uma mudança brusca da sua média. O sinal de $u\left(t_{n}\right)$ indica se a tendência é positiva $\left(u\left(t_{n}\right)>0\right)$ ou negativa $\left(u\left(t_{n}\right)<0\right)$. Calculando $u\left(t_{n}\right)$ no sentido positivo da série temporal (de $i$ até $N$ ) e depois no sentido inverso, obtém-se a distribuição $u^{*}\left(t_{n}\right)$. A intersecção das curvas de $u\left(t_{n}\right)$ e $u^{*}\left(t_{n}\right)$ mostra o ponto aproximado da mudança brusca da média.

\section{RESULTADOS E DISCUSSÃO}

Na Tabela 1 são apresentados, para cada estação, os valores das precipitações médias anuais e mensais de janeiro e de julho obtidos com a série temporal completa. Os valores das últimas três colunas da Tabela 1 indicam o aumento (diminuição) na média da última série parcial em relação à média da primeira série parcial. Para exemplificar as evoluções temporais das séries pluviométricas, a Figura 1 apresenta o comportamento temporal das médias parciais mensais e anuais para a estação de Curitiba. Nota-se que a média anual e a média do mês de julho apresentam variabilidade temporal inferior à média do mês de janeiro.

Nota-se ainda na Tabela 1, que as médias anuais variam entre 1296,9 e 1991,6 mm, enquanto que as médias para o mês de janeiro variam entre 118,1 e $289,2 \mathrm{~mm}$ e para o mês

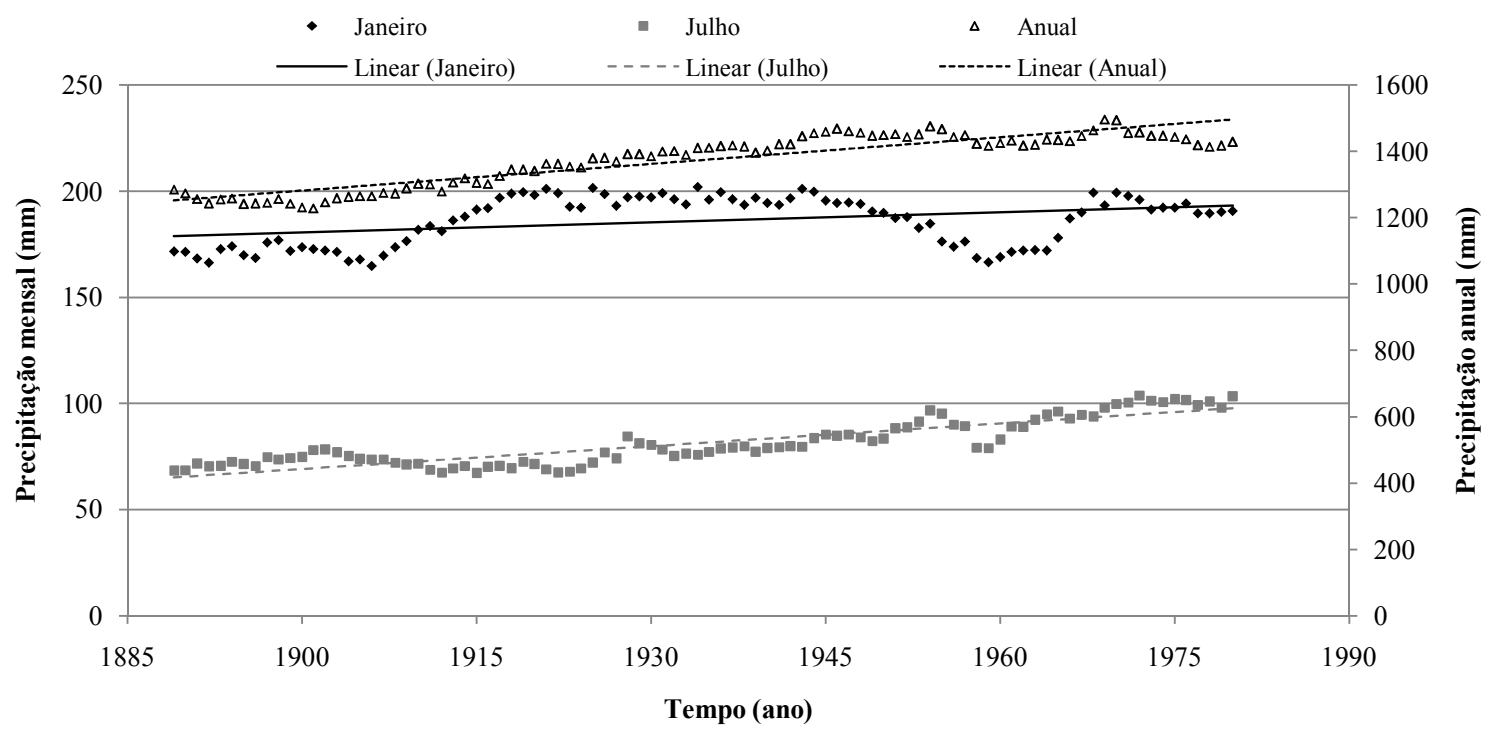

Figura 1 - Evolução temporal das precipitações médias das séries parciais da estação pluviométrica de Curitiba. 
Tabela 1 - Precipitações médias e variação das séries anuais e mensais.

\begin{tabular}{|c|c|c|c|c|c|c|c|c|}
\hline \multirow[t]{2}{*}{ Estação } & \multirow[t]{2}{*}{ UF } & \multirow[t]{2}{*}{ Período } & \multicolumn{3}{|c|}{$\begin{array}{l}\text { Precipitação média } \\
\text { (mm) }\end{array}$} & \multicolumn{3}{|c|}{$\begin{array}{l}\text { Variação das séries } \\
\text { parciais (mm) }\end{array}$} \\
\hline & & & Anual & Jan. & Jul. & Anual & Jan. & Jul. \\
\hline Tomazina & PR & $1938-2009$ & 1405,5 & 209,8 & 70,8 & 208,5 & 50,9 & 3,5 \\
\hline São Mateus Sul & PR & 1939-2008 & 1464,2 & 171,0 & 99,2 & 294,0 & 30,1 & 43,7 \\
\hline Rio Negro & PR & $1923-2009$ & 1422,4 & 165,5 & 91,8 & 441,4 & 8,6 & 68,6 \\
\hline Prudentópolis & PR & $1938-2007$ & 1559,9 & 176,1 & 102,4 & 273,2 & 79,5 & 23,9 \\
\hline Porto Amazonas & PR & $1940-2008$ & 1395,0 & 162,8 & 94,0 & 274,2 & 20,7 & 22,6 \\
\hline Morretes & PR & $1940-2009$ & 1991,6 & 289,2 & 99,3 & 451,0 & 134,0 & 64,1 \\
\hline Foz do Iguaçu & PR & $1942-2008$ & 1612,4 & 144,1 & 93,5 & 90,7 & $-15,4$ & $-0,3$ \\
\hline Curitiba & PR & $1889-2009$ & 1376,5 & 118,1 & 82,0 & 245,9 & 14,6 & 33,0 \\
\hline Vargem Bonita & $\mathrm{SC}$ & $1944-2005$ & 1854,1 & 176,3 & 123,5 & 221,4 & 28,4 & 24,4 \\
\hline Tubarão & $\mathrm{SC}$ & $1940-2006$ & 1296,9 & 142,3 & 84,9 & 329,0 & 64,5 & 41,9 \\
\hline Pouso Redondo & $\mathrm{SC}$ & $1941-2004$ & 1459,4 & 170,6 & 104,0 & 211,0 & 11,9 & 38,4 \\
\hline Pomerode & $\mathrm{SC}$ & $1930-2005$ & 1787,6 & 234,8 & 101,7 & 294,6 & 44,2 & 49,3 \\
\hline Alfredo Wagner & $\mathrm{SC}$ & $1941-2006$ & 1563,5 & 183,6 & 125,2 & 30,1 & 14,2 & 47,5 \\
\hline São Francisco de Paula & RS & $1945-2006$ & 1539,5 & 154,5 & 130,5 & 201,2 & 18,8 & 54,0 \\
\hline Canguçu & $\mathrm{RS}$ & $1943-2006$ & 1524,0 & 134.2 & 158,7 & 715,7 & 70,3 & 88,2 \\
\hline Cruz Alta & $\mathrm{RS}$ & $1945-2006$ & 1635,6 & 146,3 & 127,5 & 123,1 & 7,1 & 34,0 \\
\hline Caxias do Sul & $\mathrm{RS}$ & 1944-2006 & 1569,1 & 145,6 & 133,8 & 371,3 & 22,2 & 59,1 \\
\hline Cacequi & $\mathrm{RS}$ & 1944-2006 & 1509,0 & 125,3 & 122,2 & 203,4 & 9,9 & 35,8 \\
\hline
\end{tabular}

de julho entre 70,8 e $158,7 \mathrm{~mm}$. Comparando-se os valores médios, nota-se que a precipitação de janeiro corresponde a $9,06 \%$ da anual e ela é cerca de $60 \%$ superior aquela do mês de julho. Observa-se tendência de aumento para todas as séries. Os aumentos anuais estão compreendidos entre $90,7 \mathrm{~mm}$ (estação de Foz do Iguaçu, PR) e 715,7 mm (estação de Canguçu, RS). Para o mês de janeiro variam entre 7,1 mm (estação de Cruz Alta) e 134,0 mm (estação de Morretes, PR) e para julho, entre 3,5 mm (estação de Tomazina, PR) e 88,2 mm (estação de Canguçu, RS). Apenas a estação de Foz do Iguaçu, apresentou diminuição nos meses de janeiro $(-15,4 \mathrm{~mm})$ e de julho $(-0,3 \mathrm{~mm})$. Os resultados de aumento corroboram com aqueles obtidos por Silva et al. (2010), os quais encontraram tendências significativas de aumento do acumulado mensal desde o centro e leste de Santa Catarina até o leste do Paraná. Resultado semelhante foi encontrado por Barros et al. (2008) que mostraram uma tendência positiva na precipitação anual na América do Sul subtropical, a leste dos Andes. No noroeste da Argentina, nordeste do Uruguai e sul do Brasil foram observadas tendências de aumento de até $200 \mathrm{~mm}$, ao longo do período de 40 anos. 
Minuzzi e Caramori (2011) também encontraram aumento nas séries temporais de precipitação no estado do Paraná, principalmente no verão e na primavera. No verão, o aumento variou entre 17 e $37 \mathrm{~mm} /$ década, e na primavera, entre 16 e $42 \mathrm{~mm} /$ década. Eles observaram que as estações pluviométricas que apresentaram maiores tendências de aumento estavam situadas na metade leste do estado, em áreas próximas ao Oceano Atlântico. Deste modo, o aumento pode estar associado com chuvas oriundas da circulação marítima ou do aumento da frequência de frentes frias, conforme proposto por Cavalcanti e Kousky (2009).

Na Figura 2 é apresentada a análise de tendências das precipitações máximas com período de retorno de 100 anos, para a estação de Pomerode (SC). Na série para o mês de julho, nota-se uma mudança brusca a partir de 1953, que corresponde à primeira série parcial que inclui o ano de 1983. Esta súbita mudança na distribuição dos valores máximos está associada às chuvas anômalas observadas durante o El Niño de 19821983. Em julho de 1983, na estação de Pomerode, o total precipitado foi de 551 milímetros. Na série de janeiro e na série anual também é notada essa mudança na tendência dos valores máximos, porém com uma amplitude menor do que aquela observada para o mês de julho.

Para cada série de máximos foram obtidos os coeficientes do modelo de tendência linear. Os valores dos coeficientes $a$ e $b$ calculados para cada estação estão apresentados na Tabela 2. O valor médio de $a$ para as séries parciais anuais foi igual a $1995,3 \mathrm{~mm}$. Para o mês de janeiro foi igual a 295,0 mm e para o mês de julho de $227,3 \mathrm{~mm}$. Nota-se que a precipitação média do mês de janeiro corresponde a cerca de $15 \%$ da média anual.

Os coeficientes angulares $b$ para as precipitações anuais e do mês de janeiro foram positivos em 16 das 18 estações e em 17 estações para as séries de julho. Esses coeficientes variaram entre 0,2, no mês de julho na estação de Vargem Bonita e 29,43, na estação de Canguçu, para a precipitação anual. Os valores médios de $b$ são de 7,93 para as séries parciais anuais, 2,33 para as séries do mês de janeiro e 2,74 para as séries do mês de julho. Esses valores indicam um aumento da média da série parcial de 30 anos a um nível de significância de 5\%. Para o mês de janeiro apenas a estação de São Francisco de Paula não apresentou significância estatística para o nível estabelecido, enquanto para as séries do mês de julho, os coeficientes angulares não foram estatisticamente significativos em quatro estações pluviométricas.

Na Figura 3 é apresentada a comparação entre as precipitações máximas diárias anuais com período de retorno de 100 anos da primeira (30 anos iniciais da série completa) e da última (30 anos finais da série completa) série parcial. Nota-se que em 15 das 18 estações resultaram valores mais elevados na última série parcial. A média dos acréscimos foi de $26 \%$, com valor máximo de $82 \%$ na estação de Prudentópolis (PR). Nas três estações que apresentaram redução, o decréscimo médio foi de apenas 4,1\%. Esta variação nas séries históricas pode ter efeitos importantes na prática de projetos de drenagem urbana e controle de erosão do solo, onde as intensidades de precipitação utilizadas são estimadas pela série de máximos valores diários anuais (Back et al., 2012). Também é possível que estas pequenas diferenças estejam associadas aos diferentes períodos de dados de cada série.

Na Figura 4 são apresentados os coeficientes angulares $b$ da linha de tendência ajustada a série estimada de precipitações máximas diárias anuais, com período de retorno de 100 anos para cada estação pluviométrica. Os coeficientes foram positivos em 14 das 18 estações. A análise estatística das linhas de tendência mostrou que todos os coeficientes apresentaram significância ao nível de 5\%. As cinco estações do Rio Grande do Sul

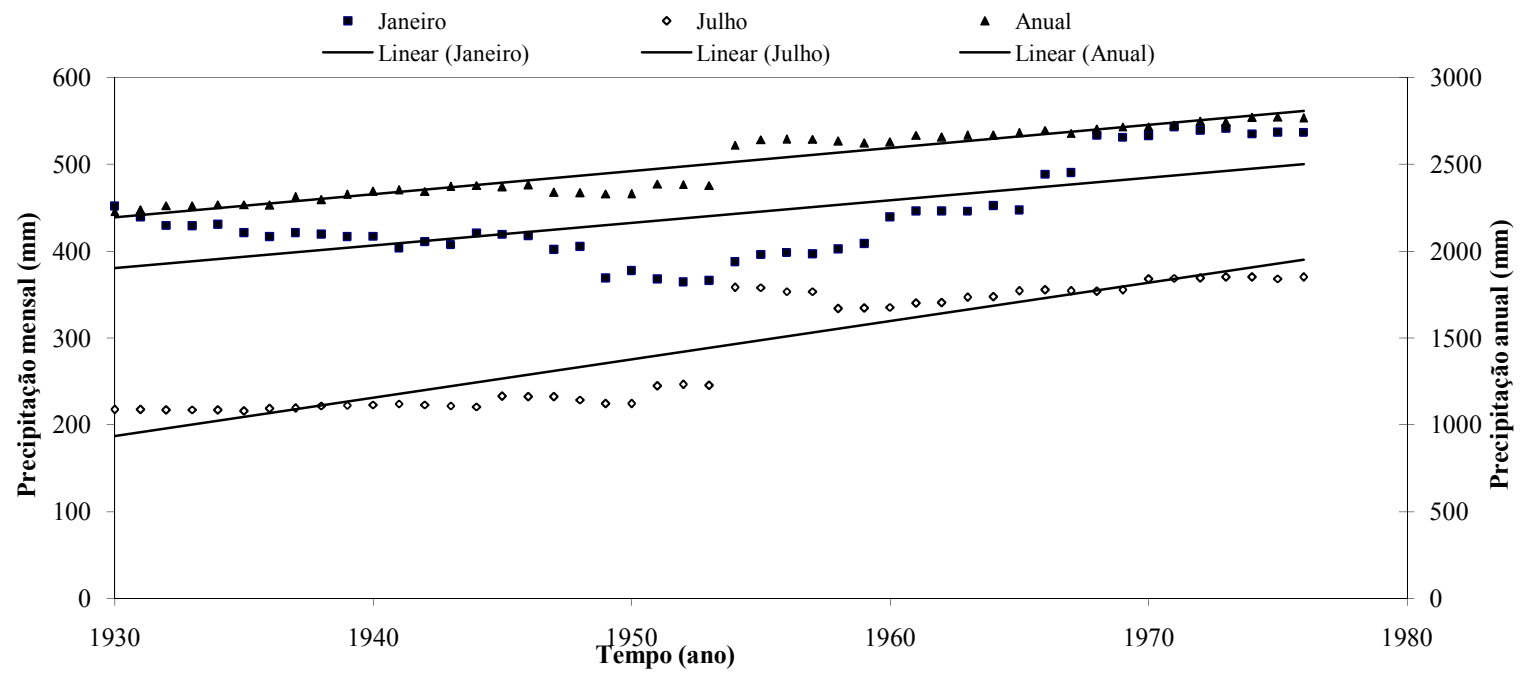

Figura 2 - Evolução da precipitação anual e mensal com período de retorno de 100 anos para a estação de Pomerode - SC. 
Tabela 2 - Coeficientes da função linear(1) das séries de precipitações anuais e mensais com período de retorno de 100 anos,

\begin{tabular}{|c|c|c|c|c|c|c|c|c|}
\hline \multirow[t]{2}{*}{ Estação } & \multirow[t]{2}{*}{$\mathbf{U F}$} & \multirow[t]{2}{*}{ Período } & \multicolumn{3}{|c|}{ Coeficiente $a$} & \multicolumn{3}{|c|}{ Coeficiente $b$} \\
\hline & & & Anual & Jan. & Jul. & Anual & Jan. & Jul. \\
\hline Tomazina & PR & 1938-2009 & 1886,0 & 322,0 & 244,0 & $4,52^{*}$ & $3,6^{*}$ & $-0,95^{*}$ \\
\hline São Mateus Sul & PR & 1939-2008 & 1943,0 & 275,5 & 255,4 & $10,61^{*}$ & $2,49 *$ & $3,06^{*}$ \\
\hline Rio Negro & PR & $1923-2009$ & 1694,0 & 298,0 & 175,0 & $12,53^{*}$ & $1,11^{*}$ & $3,2^{*}$ \\
\hline Prudentópolis & PR & $1938-2007$ & 2072,6 & 215,2 & 278,0 & $10,98^{*}$ & $7,0^{*}$ & 0,19 \\
\hline Porto Amazonas & PR & $1940-2008$ & 1895,6 & 260,5 & 258,6 & $7,18^{*}$ & $2,4^{*}$ & 0 \\
\hline Morretes & PR & 1940-2009 & 833,2 & 181,1 & 161,6 & $-1,83^{*}$ & $4,24 *$ & $1,01^{*}$ \\
\hline Foz do Iguaçu & PR & $1942-2008$ & 2504,6 & 378,0 & 260,9 & $2,14^{*}$ & $-1,28^{*}$ & $1,94 *$ \\
\hline Curitiba & PR & 1889-2009 & 1249,7 & 178,7 & 64,7 & $2,37^{*}$ & $1,23^{*}$ & $1,19^{*}$ \\
\hline Vargem Bonita & $\mathrm{SC}$ & 1944-2005 & 2760,4 & 367,6 & 284,0 & $3,27^{*}$ & $0,5^{*}$ & 0,2 \\
\hline Tubarão & $\mathrm{SC}$ & 1940-2006 & 1750,6 & 230,4 & 158,1 & $11,47^{*}$ & $4,21^{*}$ & $3,85^{*}$ \\
\hline Pouso Redondo & $\mathrm{SC}$ & $1941-2004$ & 1868,1 & 315,3 & 203,0 & $14,92^{*}$ & $1,56^{*}$ & $5,74 *$ \\
\hline Pomerode & $\mathrm{SC}$ & $1930-2005$ & 2182,6 & 378,3 & 182,7 & $10,74^{*}$ & $2,08^{*}$ & $3,58^{*}$ \\
\hline Alfredo Wagner & $\mathrm{SC}$ & $1941-2006$ & 2262,4 & 367,8 & 233,3 & $3,41^{*}$ & $0,5^{*}$ & $6,3^{*}$ \\
\hline São Francisco de Paula & RS & $1945-2006$ & 2152,3 & 337,0 & 230,9 & $2,29^{*}$ & 4,76 & 3,05 \\
\hline Canguçu & RS & $1943-2006$ & 1928,1 & 235,2 & 309,0 & $29,43^{*}$ & $4,08^{*}$ & $7,42 *$ \\
\hline Cruz Alta & RS & $1945-2006$ & 2520,8 & 314,2 & 242,1 & $-0,11$ & $2,44 *$ & $4,22 *$ \\
\hline Caxias do Sul & RS & 1944-2006 & 2148,0 & 270,4 & 218,4 & $10,87^{*}$ & $2,48^{*}$ & $4,68^{*}$ \\
\hline Cacequi & RS & 1944-2006 & 2263,3 & 385,2 & 331,0 & $7,86^{*}$ & $-1,43^{*}$ & $0,64 *$ \\
\hline
\end{tabular}

(1) Função linear y = a +b.x; * Significativo ao nível de 95\%.

apresentaram tendências de crescimento positivo, enquanto que no estado de Santa Catarina, as estações de Pomerode e Alfredo Wagner apresentaram tendência negativa, com valores de $b$ iguais a $-0,42$ e $-0,47$, respectivamente. O maior valor foi obtido para a estação de Prudentópolis $(b=2,68)$. Este valor representa um aumento de $2,68 \mathrm{~mm}$ por ano na precipitação máxima diária anual.

Penalba e Robledo (2010) também encontraram aumento de precipitação diária na região sul do Brasil, especialmente de eventos extremos no verão, outono e primavera. Conforme mostram Kayano e Sansigolo (2009), as precipitações intensas podem ser causadas pela intensificação dos complexos convectivos de mesoescala, que são mais comumente encontrados no lado oeste do Sul do Brasil, provenientes do Paraguai ou Argentina..

Eventos extremos de precipitação no estado de Santa Catarina também foram avaliados por Campos et al. (2006) para o período de 1911-2006. Na maioria das regiões estudadas os totais anuais de precipitação apresentaram tendência de aumento. No município de Chapecó, foi observado um aumento de 37,7 mm na precipitação anual ao longo dos últimos 38 anos. Os totais anuais apresentaram aumento, mas ao mesmo tempo, 


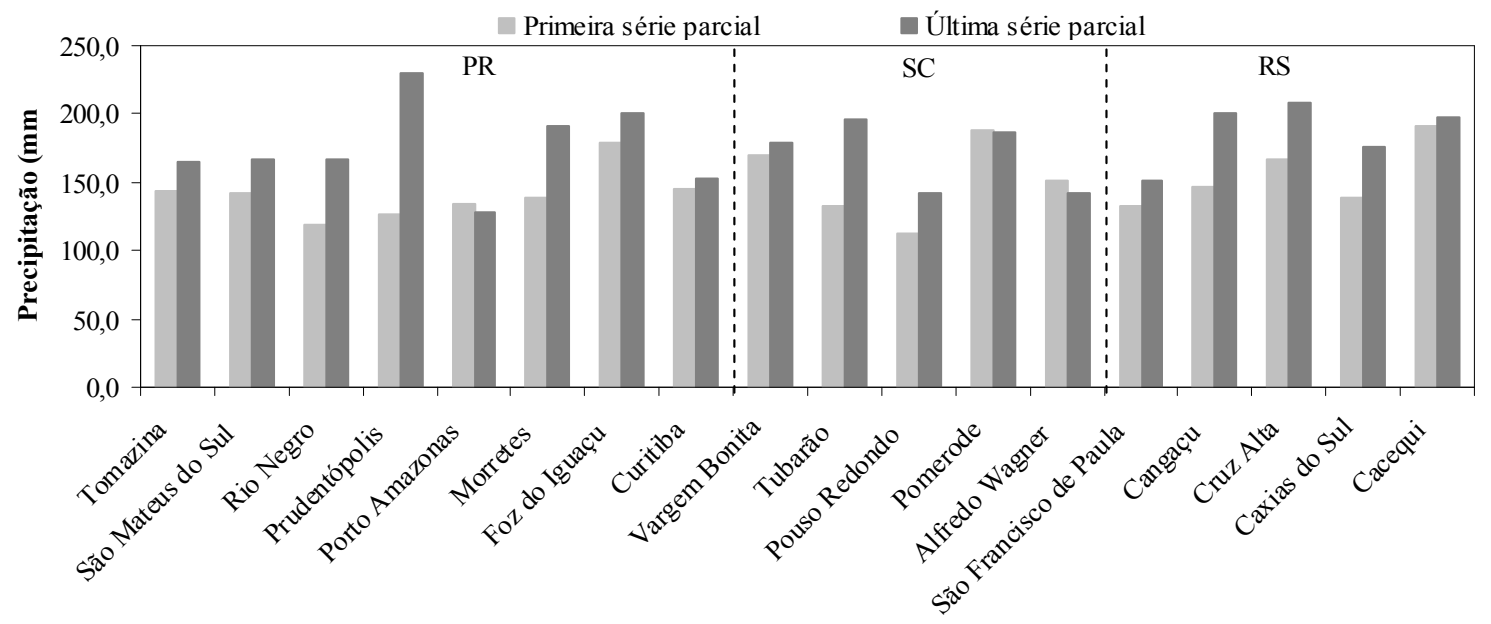

Figura 3 - Precipitações máximas diárias com período de retorno de 100 anos, para a primeira e última série parcial.

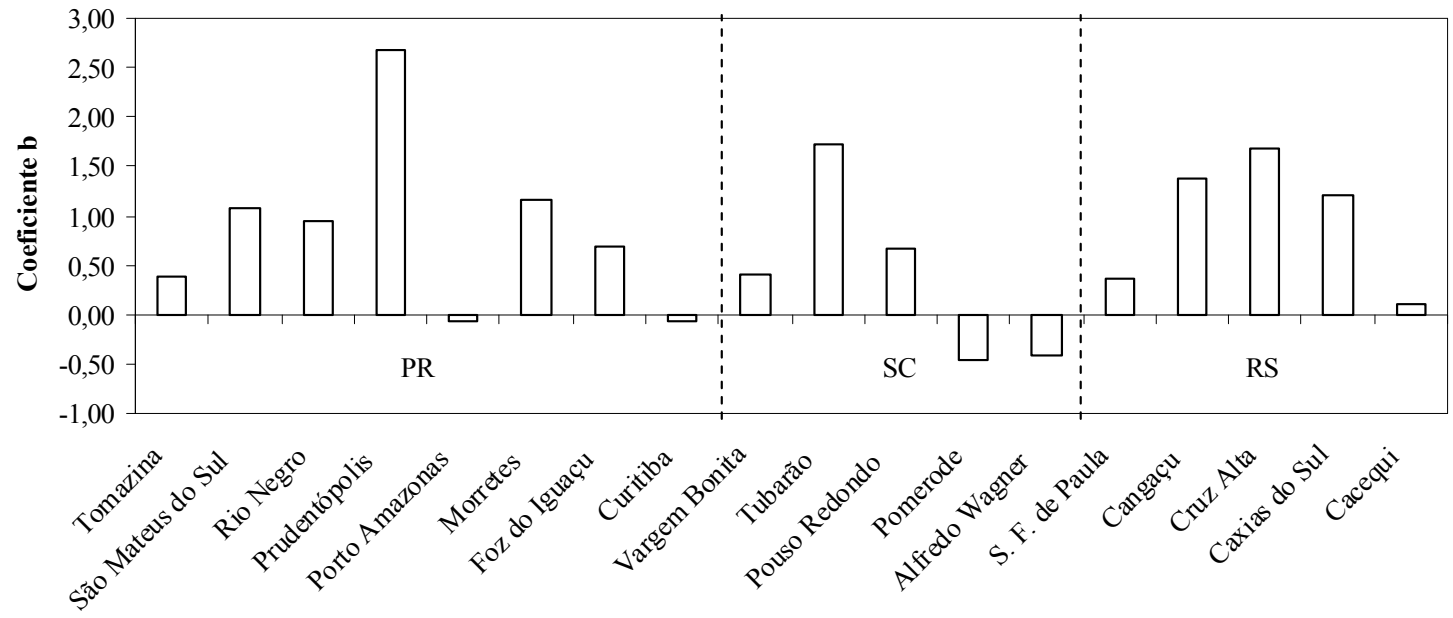

Figura 4 - Coeficiente angular b da linha de tendência das precipitações máximas diárias anuais, com período de retorno de 100 anos.

o número de dias consecutivos sem chuva também aumentou juntamente com o aumento de precipitações acima de $100 \mathrm{~mm}$. Estes resultados foram verificados em diferentes regiões do Estado de Santa Catarina.

Uma possível explicação para o aumento na quantidade dos eventos de precipitação intensa foi apresentada por Molion (2008). Segundo o autor, durante a fase fria da Oscilação Decadal do Pacífico (ODP), a última da qual possivelmente se iniciou no final da década de 1990, a troposfera permanece relativamente mais fria e os complexos convectivos (CCS) exigem mais energia para se desenvolver e produzir precipitação. Assim, os topos dos CCS atingem alturas mais elevadas, produzindo maiores totais pluviométricos comparados com aqueles produzidos durante a fase quente da ODP.

O resultado do teste de Mann-Kendall aplicado para identificar mudanças na média de cada série temporal é apresentado na Figura 5. A linha azul representa a série $U\left(t_{n}\right)$ e a linha na cor rosa, a série $U^{*}\left(t_{n}\right)$. As linhas horizontais representam os intervalos de confiança bilaterais de $95 \%$, sendo que, uma tendência é considerada significativa quando os valores absolutos de $U\left(t_{n}\right)$ são maiores do que o limite de confiança. A data da mudança brusca na média da série é identificada no ponto de interseção entre as duas curvas se ela ocorrer dentro dos valores críticos do intervalo de confiança.

A característica das séries apresentadas indica uma alteração no comportamento da média anual ao longo do tempo. Nota-se, novamente, um incremento das precipitações na maioria das estações analisadas, com tendências significativas ao nível de $95 \%$, em dezesseis séries completas analisadas. Diversas séries apresentaram alteração no comportamento da sua média entre as décadas de 1970 e 1980. Este período é reconhecido como o desvio climático mais intenso associado com a Oscilação Decadal do Pacífico (Kayano et al. 2008) e poderia explicar as alterações na média encontradas neste estudo. 


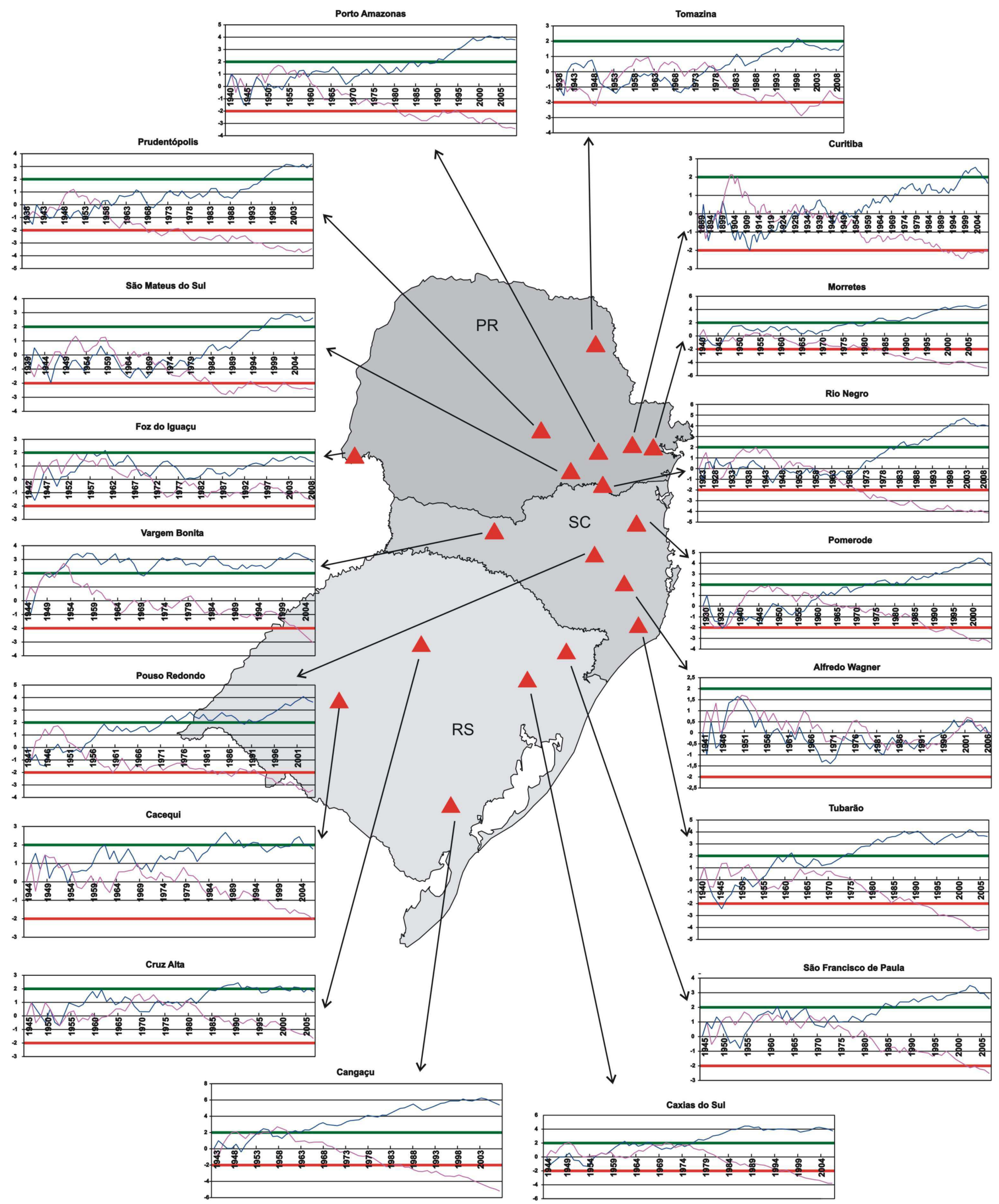

Figura 5 - Evolução de U(t) da precipitação anual do teste de Mann-Kendall. As linhas horizontais pontilhadas indicam significância ao nível de $95 \%$. 
$\mathrm{Na}$ estação de Curitiba, observa-se uma mudança brusca na média da série em 1946, mas que somente se tornou significativa em 1997. A série de Pomerode apresentou uma mudança na média em 1960, mas adquiriu significância estatística apenas em 1972. A série de São Francisco de Paula apresentou mudança na média em 1972, significativa a partir de 1980.

Comportamento semelhante foi verificado nas estações de Tomazina, com significância somente a partir de 1997, São Mateus do Sul, em 1996; Rio Negro, em 1982; Prudentópolis, em 1995, Porto Amazonas, em 1989 e Morretes, em 1980. Embora a média anual da estação de Foz do Iguaçu tenha apresentado tendência de acréscimo, esta tendência não é significativa ao nível de 95\%, pelo teste de Mann-Kendall.

Em Santa Catarina as médias anuais das estações de Vargem Bonita, Tubarão e Pouso Redondo, apresentaram tendências positivas, significativas ao nível de $95 \%$, somente a partir de 1950, 1973 e 1971, respectivamente. A média anual da estação de Alfredo Wagner não apresentou significância estatística, embora tenha apresentado tendência significativa nos valores ajustados pelo parâmetro da distribuição Normal.

A análise de tendência para as estações do Rio Grande do Sul mostra um acréscimo das precipitações nas estações de Cruz Alta, com significância estatística em 1986, Caxias do Sul, em 1976, Canguçu, em 1960 e Cacequi, em 1984. Entretanto, Winke et al. (2008) analisando dados de precipitação e de temperatura do município de Pelotas, no período de 1931 a 2007, observaram tendência crescente na temperatura mínima anual, mas nenhuma tendência significativa na precipitação.

De acordo com Obregón Párraga (2003), a leste da Cordilheira dos Andes, no Sul e Sudeste brasileiro, a variabilidade observada nas séries de chuvas anuais parece evidenciar saltos nos valores médios, dividindo as séries em dois períodos distintos, a partir metade da década de 1970 . No presente estudo, a mudança no comportamento da média aparece em diferentes períodos que vão desde a segunda metade da década de 1940 até a década de 1990.

\section{CONCLUSÕES}

Foram analisados dados de chuva de 18 estações pluviométricas pertencentes à Agência Nacional de Águas com amostras superiores a 40 anos e localizadas nos três estados da Região Sul do Brasil. Eventuais falta de dados foram preenchidas de forma a se constituir uma série temporal completa para o período disponível. As análises das séries mensais e anuais evidenciaram tendências estatisticamente significativas ao nível de $5 \%$ de aumento dos totais precipitados para o período analisado. O mês de janeiro apresenta tendência de aumento em todas as estações pluviométricas do Paraná, exceto na estação de Foz do Iguaçu. Todas as estações de Santa Catarina apresentam tendência positiva e, no Rio Grande do Sul, três estações apresentam tendência positiva, enquanto duas apresentam tendência de decréscimo das precipitações. As precipitações máximas diárias apresentam tendência de aumento ao longo do tempo, em 14 das 18 estações pluviométricas.

O teste de Mann-Kendall mostrou tendências significativas ao nível de $95 \%$ em 16 das 18 estações analisadas. As exceções foram as estações de Foz do Iguaçu-PR e de Alfredo Wagner-SC, cujo teste de tendência não apresentou significância estatística e que mudanças nas séries temporais ocorreram em períodos distintos, não confirmando, portanto, os resultados encontrados em outros estudos. Diversas séries apresentaram alteração no comportamento da sua média entre as décadas de 1970 e 1980. Este período é reconhecido como o desvio climático mais intenso associado com a Oscilação Decadal do Pacífico (Kayano et al., 2008) e poderia explicar as alterações na média encontradas neste estudo.

\section{AGRADECIMENTOS}

Agradecemos ao MCT/FINEP/AÇÃO TRANSVERSAL - Previsão de Clima e Tempo 04/2008, convênio 01.08.0568.00, pelo financiamento de pesquisa, a CAPES pela bolsa do segundo autor e aos revisores por suas preciosas contribuições que foram fundamentais ao aprimoramento deste documento.

\section{REFERÊNCIAS}

ALEXANDER, L. V. et al; Global observed changes in daily climate extremes of temperature and precipitation. Journal of Geophysical Research, v. 111, D05109, p. 1-22, 2006.

BACK, Á J.; OLIVEIRA, J. L. R.; HENN, A. Relações entre precipitações intensas de diferentes durações para desagregação da chuva diária em Santa Catarina. Revista Brasileira de Engenharia Agrícola e Ambiental, v. 16, n.4, p. 391-398. 2012.

BARROS, V. R.; DOYLE, M. E.; CAMILLONI, I. A. Precipitation trends in southeastern South America: relationship with ENSO phases and with low-level circulation. Theoretical and Applied Climatology. v. 93, p. 19-33, 2008.

BURN, D. H.; SHARIF, M.; ZHANG, K. Detection of trends in hydrological extremes for Canadian watersheds. Hydrological Processes. v.24, p.1781-1790, 2010.

CAMPOS, C.; ALVES, R.; BRAGA, H. J. Mudanças climáticas atuais e seus impactos no Estado de Santa Catarina. Agropecuária Catarinense, v. 19, p. 31-35, 2006.

CAVALCANTI, I. F. A.; KOUSKY, V. E. Frentes frias sobre o Brasil. In: Cavalcanti, I. F. A.; Ferreira, N. J.; Justi da 
Silva, M. G. A.; Silva Dias, M. A. F. (Eds.) Tempo e clima no Brasil. São Paulo, Oficina de Textos. 2009. p.135-148.

GALLANT, A. J. E.; HENNESSY, K. J.; RYSBEI J. Trends in rainfall indices for six Australian regions: 1910-2005. Australian Meteorological Magazine. v. 56, p. 223-239, 2007.

GEMMER, M.; BECHER, S.; JIANG, T. Observed monthly precipitation trends in China 1951-2002. Theoretical and Applied Climatology, v. 77, n.1-2, p. 39-45, 2004.

HAYLOCK, M.; NICHOLLS, N. Trends in extreme rainfall indices for an updated high quality data set for Australia, 1910-1998. International Journal of Climatology, v.20, p.1533-1541, 2000.

HAYLOCK, M.R. et al. Trends in total and extreme South American rainfall 1960-2000 and links with sea surface temperature. Journal of Climate, v. 19, p. 1490-1512, 2006.

KAYANO, M. T.; SANSÍGOLO, C. Interannual to decadal variations of precipitation and daily maximum and daily minimum temperatures in southern Brazil. Theoretical and Applied Climatology, v.97, p.81-90, 2009.

KAYANO, M. T.; OLIVEIRA, C. P.; ANDREOLI, R. V. Interannual relations between South American rainfall and tropical sea surface temperature anomalies before and after 1976. International Journal of Climatology, v.29, p.1439-1448, 2008.

MINUZZI, R. B.; CARAMORI, P. H. Variabilidade climática sazonal e anual da chuva e veranicos no Estado do Paraná. Rev. Ceres, Viçosa, v. 58, n.5, p. 593-602, set/out, 2011.

MOLION, L.C.B. Perspectivas climáticas para os próximos 20 anos. Revista Brasileira de Climatologia, v.3/4, p. 117-128, 2008.

NAGHETTINI, M.; PINTO, É. J. A. Hidrologia Estatística. Belo Horizonte, CPRM, 2007, 561 p.

OBREGÓN PÁRRAGA. G. O. Dinâmica da variabilidade climática da precipitação sobre a América do Sul. Tese (doutorado). São José dos Campos: INPE, 2003.

PENALBA, O.C.; ROBLEDO, F. A. Spatial and temporal variability of the frequency of extreme daily rainfall regime in the La Plata Basin during the 20th century. Climatic Change, v. 98, p.531-550, 2010.
ROY, S. S.; BALLING JR, R. C. Trends in extreme daily precipitation indices in India. International Journal of climatology. v.24, p.457-466, 2004.

SANSIGOLO, C. A. Distribuição de extremos de precipitação diária, temperatura máxima e mínima e velocidade do vento em Piracicaba, SP (1917-2006). Revista Brasileira de Meteorologia, v.23, n.3, p.341-346, 2008.

SANSIGOLO, C. A.; KAYANO, M. T. Tendências nas temperaturas máximas e mínimas e nas precipitações sazonais do Rio Grande do Sul (1913-2006). In: XII Congresso Brasileiro de Meteorologia, Anais... Belém, 2010.

SANT'ANNA NETO, J. L. Avaliação das mudanças no regime das chuvas do Estado de São Paulo durante um século (1988 - 1993). Acta Scientiarum, v. 21, n. 4, p. 915-921, 1999.

SILVA, F. D. dos S.; FERREIRA, D. B.; SARMANHO, G. F.; SANTOS, L. S. F. C. dos; FORTES, L. T. G.; PARENTE, E. G. P. Tendência de alterações climáticas da precipitação observadas no Brasil de 1961 a 2008 utilizando dados gradeados. In: XII Congresso Brasileiro de Meteorologia, Anais... Belém, 2010.

SNEYERS, R. Sur l'analyse statistique des séries d'observations. Genève: Organisation Météorologique Mondial, 1975.

STRECK, N. A. Associação da variabilidade da precipitação pluvial em Santa Maria com a Oscilação Decadal do Pacífico. Pesquisa Agropecuária Brasileira, Brasília, v. 44, n.12, p. 1553-1561, 2009.

TUCCI, C. E. M. Hidrologia: ciência e aplicação. 4 ed. Porto Alegre: Ed. Universidade/UFRGS, 2004, 943 p.

WINKE L. O. L.; DAMÉ, R. de C. F. TEIXEIRA, C. F. A.; MACHADO, A. A.; ROSSKOFF, J. L. C. Caracterização climática e estudo de tendências nas séries temporais de temperatura e precipitação em Pelotas/RS. In: XVII Congresso de Iniciação Científica. X Encontro de PósGraduação, Anais... São Paulo, 2008. 